\title{
Maternal and infant characteristics connected to shared pleasure in dyadic interaction
}

Kaija Puura, MD, PhD1, Jukka Leppänen, PhD2, Raili Salmelin, MSc, PhD3, Mirjami Mäntymaa,

MD, PhD,1,4, Ilona Luoma, MD, PhD5, Reija Latva, MD, PhD1, Mikko Peltola, PhD6, Terho Lehtimäki, MD, PhD7 and Tuula Tamminen, MD, PhD8

1) Department of Child Psychiatry, Tampere University Hospital, and Centre for Child Health Research, Faculty of Medicine and Health Technology, Tampere University, Tampere, Finland

2) Centre for Child Health Research, Faculty of Medicine and Health Technology, Tampere University, Tampere, Finland

3) Faculty of Social Sciences, Health Sciences, Tampere University, and Department of Child Psychiatry, Tampere University Hospital, Tampere, Finland

4) Department of Child Psychiatry, South Ostrobotnia Central Hospital, Seinäjoki, Finland

5) Institute of Clinical Medicine, School of Medicine, Faculty of Health Sciences, University of Eastern Finland, and Department of Child Psychiatry, Centre of Peadiatric and Adolescent Medicine, Kuopio University Hospital, Kuopio, Finland

6) Human Information Processing Laboratory, Faculty of Social Sciences, Tampere University, Tampere, Finland

7) Department of Clinical Chemistry, Fimlab Laboratories, Cardiovascular Research Centre, Tampere, and Faculty of Medicine and Life Sciences, Tampere University, Tampere, Finland.

8) Department of Child Psychiatry, Tampere University, Tampere, Finland

Corresponding author:

Kaija Puura 
Department of Child Psychiatry, Tampere University Hospital and Centre for Child Health Research, Faculty of Medicine and Health Technology, Tampere University, Po Box 2000, Tampere University Hospital, 33521 Tampere, Finland

Kaija.puura@tuni.fi

The authors do not have any conflict of interests

Acknowledgements

The Study has been financially supported by the Academy of Finland (grants no. 141037 for T.T, 286284 for T.L), Competitive State Research Financing of the Expert Responsibility area of Tampere (grants 9S502, 9T051, X51001); Finnish Foundation for Cardiovascular Research (for T.L); Tampere Tuberculosis Foundation; Yrjö Jahnsson Foundation; Signe and Ane Gyllenberg Foundation; Diabetes Research Foundation of Finnish Diabetes Association: and EU Horizon 2020 (grant 755320 for TAXINOMISIS for T.L). 
The aim of the study was to analyse which maternal factors (depressive symptoms, effect of life events, maternal sensitivity and structuring) and infant characteristics (temperament, social withdrawal symptoms, interactive behaviour, genotype, gender) contribute to shared pleasure (SP) in parent-infant interaction. The participants were 113 mother-infant dyads. The mothers filled in the Edinburgh Postnatal Depression Scale, the Infant Behavior Questionnaire, and the Life Events Questionnaire. The dyads were videotaped in a free play situation and the videos were analysed using the Alarm Distress Baby Scale and the Emotional Availability Scales. The infants were genotyped for four genes involved in emotion regulation. The occurrence and duration of SP (SP-MD) in mother-infant interactions were analysed from the videotapes. Higher maternal sensitivity and depressive symptoms, better infant responsiveness, and the infant having the GG variant of the gene TPH2 -307 were associated with the occurrence of SP. Lower level depressive symptoms, better maternal structuring, and greater infant involvement were associated with the longer duration of SP. Those dyads where the mother and infant were best able to read each other's positive cues and to respond to them were more likely to experience mutual positive affect, as seen in SP. 
From an evolutionary perspective, emotions are fundamentally integrative and interconnecting, in addition to being a means of sharing between individuals (Cole et al., 1994; Darwin, 1872; Siegel, 2001). Facial expressions conveying basic emotions (e.g. happiness, sadness, anger, fear) are considered a universal and fast-operating channel for communicating whether one is about to attack, flee, or embrace (Ekman, 1971). Throughout our lives, emotions influence cognition, especially attention, memory, and reasoning (Dolan, 2002). Emotions also bind us to one another in long-term, mutually beneficial relationships, including the parent-child relationship (Schelling, 1963; Trevarthen \& Aitken, 2001).

Positive emotions - including joy, happiness, affection, empathy, and compassion - are fundamental markers of an individual's well-being, and are independent of negative emotions (Watson \& Tellegen, 1985). Both smiling and laughter produce opioid release, a lower respiratory rate, and activity in the autonomic nervous system; furthermore, the ability to have fun and experience joy has been shown to be connected to psychological resilience and favourable health outcomes (Bonanno, 2004; Dockray \& Steptoe, 2010). Positive emotions shared in meaningful relationships build people's physical, intellectual, social, and psychological resources throughout their lifespan (Fredrickson, 2004; Ramsey \& Gentzler, 2015). Positive affectivity can be seen as reward-motivated behaviour, and subjective positive affectivity can be seen as an emotional state elicited by rewards (Rolls, 1999; Schultz, 2000). In humans, the ability to experience positive affect like pleasure and contentment, and the ability to show this with smiling and laughter, emerges early in development (Emde \& Harmon, 1972). At the age of two months, emotional expressions are coordinated with visual attention, and interactions including sequences of shared smiles emerge in parent-infant dyads (Feldman, 2007). An interesting recent finding showing that direct gaze strengthens bidirectional adult-infant neural connectivity during communication (Leong et al., 2017) raises the question of whether the shared smile with simultaneous eye contact might have a role of its own in early interaction.

Infants develop their ability to experience, share, express, and regulate positive affective states from parent-infant interaction, with the parents' empathic understanding and attunement to the infant's affective state creating the basis for the infants' own emotion regulation (Manian \& Bornstein, 2009; Schore, 2001). Maternal sensitivity is the mother's ability to perceive and infer the meaning behind her infant's behavioural signals, and to respond to them promptly and appropriately; high maternal sensitivity has been associated with better infant outcome (e.g. Blehar, Lieberman, \& Ainsworth, 1977; Bornstein \& Tamis-LeMonda, 1989; Mäntymaa et al., 2004). Another feature of good parent-infant interaction is the parent's ability to structure the environment and interaction 
situations so that the infant can be an active partner in the dyadic interaction and perform in an optimal way within his/her capacity (e.g. Biringen, 2008; Stern, 1971). Maternal behaviour in interaction is associated with the amount of expressed positive emotions: when mothers direct positive behaviours towards their infants, infants start to respond more frequently to them (Kaye \& Fogel, 1980; Olino et al., 2011). In typical development, the amount of expressed positive emotions between a mother and her infant increases with time (Denham, Lehman, Moser, \& Reeves, 1995; Malatesta, Grigoryev, Lamb, Alvin, \& Culver, 1986; Olino et al., 2011), although Sallquist et al. (2010) have reported a decline after 19 months of age.

Many factors contribute to maternal behaviour in interaction. Many studies across diverse ethnic and socioeconomic groups have shown that maternal postnatal depression is associated with less optimal parenting behaviour and negative child outcome (Field, 2010; Goodman et al., 2011; Wachs, Black, \& Engle, 2009). However, there is some variability across studies. Campbell, Cohn, and Meyers (1995) found that women whose depression lasted six months were less positive with their infants than women whose depression was more short-lived, and their babies were less positive during face-to-face interaction. Lovejoy, Graczyk, O’Hare, and Neuman (2000) found a strong association between parental depression and negative parenting behaviours, but only a weak association between depression and lowered positive parenting behaviours, while Field et al. (2006) found that depressed mothers and their infants expressed fewer positive emotions and spent more time matched in negative behavioural states than in positive behavioural states. Respectively, in their meta-analyses, Goodman et al. (2011) found a stronger association between maternal depression and negative rather than positive child affectivity. It seems that despite their depression, some mothers show good interaction with their children (e.g. Field, Hernandez-Reif, Schanberg, \& Kuhn, 2003; Frankel \& Harmon, 1996). According to Field et al. (2003), infants of 'good interaction' depressed mothers were less dysregulated, which may have contributed to their mothers being 'good interaction' partners. The balance between positive and negative emotions shared in parent-infant interaction and the infant's own characteristics could be factors explaining the variation found in the outcome of depressed parents' children.

In addition to postnatal depression, both stressful life events and daily stressors may have a negative impact on parenting behaviours (Abidin, 1992; Dyb, Jensen, \& Nygard, 2011; Tein, Sandler, \& Zautra, 2000). Psychological distress caused by stressful life events may make parents more negative, intrusive, and hostile towards the infant's or toddler's attempts at autonomy and social behaviour, and less sensitive and responsive in face-to-face interactions (Campbell, 1995; Choe, Olson, \& Sameroff, 2013; Tein et al., 2000). The infants of mothers who were under greater stress were less responsive and less clear in the cues they provided, suggesting that a circular feedback loop 
may exist in such relationships (Crnic, Greenberg, Ragozin, Robinson, \& Basham, 1983). This in turn can result in poorer self-regulation skills and increased negative affectivity (Boe et al., 2014; Choe et al., 2013). Although there are studies on how people experiencing stressful life events have reported frequent positive emotions (Folkman \& Moskowitz, 2000), less is known about how stressful life events may affect the expression of positive emotions in parent-infant interaction.

The level of positive affectivity expressed in parent-infant interaction may also depend on infant characteristics, such as gender and temperament. Temperament refers to biologically based individual differences in behaviour and affectivity that are stable across time and situation (Rothbart, Ahadi, \& Evans, 2000). Positive and negative affectivity are often seen as separate dimensions of temperament (Aksan et al., 1999; Rothbart \& Bates, 2006) and defined as a set of constitutionally based traits that form the core of the personality and influence the direction of development (Rothbart \& Bates, 2006).

In their meta-analysis examining sex differences in various aspects of temperament, ElseQuest, Hyde, Goldsmith, and Van Hulle (2006) found that at the age of 13 months, girls were higher in positive affects than boys, but boys were higher in high-intensity positive affects than girls. They also found only negligible differences in boys' and girls’ negative affects. By contrast, a review by Schore (2017) found that three- to four-month-old infant boys showed higher levels of negative affectivity in caretaking activities and were less able to down-regulate their frustration; furthermore, mothers regulated the states of their infant boys less well than they did their infant girls. Schore argues that due to their less mature self-regulation skills, infant boys could be more vulnerable to environmental stressors, such as poor mother-infant interaction, compared to infant girls. Negative affectivity or a difficult temperament have generally been regarded as vulnerability factors, but according to the differential susceptibility hypothesis (e.g. Belsky \& Pluess, 2009), they may also be explored as plasticity factors enhancing a developing child's sensitivity to both risk and protective environmental factors.

Infants' interaction skills for signalling their needs include the ability to initiate and maintain eye contact with another person, vocalize, and use facial expressions and body and head movements to engage the caregiver (Emde, 1983; Farroni, Csibra, Simion, \& Johnson, 2002; Trevarthen \& Aitken, 2001). Infants who are active in signalling involve the caregiver in interaction and respond positively to the parents' or caregivers' actions are more likely to get a sensitive response (Biringen, 2000). Withdrawal is to a certain degree a normal feature of infant behaviour in parentinfant interactions and a way for the infant to regulate the flow of interaction (Cohn \& Tronick, 1989; Tronick, 1989). However, increased or sustained withdrawal reaction in infants can be observed in unsatisfactory parent-infant interactions (Guedeney \& Fermanian, 2001; Puura, Guedeney, 
Mäntymaa, \& Tamminen, 2007). Sustained withdrawal from social interaction may in turn reduce the infant's capacity to notice and respond to expressed positive emotions in interaction with the parent.

Experiencing and expressing emotions may also be dependent on our genetic constitution (Davis \& Suveg, 2014). The functional polymorphism of several genes included in the serotonin functions of the brain has been found to be associated with mood regulation in both human and animal research (e.g. Carver, Johnson, \& Joormann, 2008; Fakra et al., 2009; Hairiri \& Holmes, 2006; Zhang \& Meaney, 2010). In their groundbreaking study, Caspi et al. (2003) found that severe childhood maltreatment was associated with more depression symptoms in adulthood in individuals that carried one or two copies of the short allele of the serotonin transporter gene 5-HTTLPR, but not in individuals homozygous for the long allele. More recently, serotonin transporter polyadenylation polymorphism (STPP) has been found to be associated with anxiety and depression in a similar manner, with the $\mathrm{G}$ allele associated with increased risk (Hartley et al., 2012). In the serotonin system, functional polymorphism of two other genes - the gene that encodes tryptophan hydroxylase isoform 2 (TPH2 -703) and the promoter of the serotonin autoreceptor 1A gene (HTR1A-1019) - have also been associated with disorders of emotion regulation (Fakra et al., 2009; Gutknecht et al., 2008). Since the polymorphism of these genes is associated with the risk for negative emotionality at least in unfavourable environmental conditions, it might also play a role in positive emotionality and the infant's capacity to take part in shared pleasure in parent-infant interaction.

Another aspect linked to experiencing shared pleasure with others is the ability and willingness of an individual to engage in interaction. Oxytocin has recently been the subject of interest in many studies because it has been strongly linked to parent-infant attachment, and also to social skills in general (Curley \& Keverne, 2005). A consistent pattern has emerged in recent studies linking oxytocin receptor gene (OXTR) polymorphism with levels of prosocial behaviour, ranging from activity in emotion-related brain areas during the perceptual processing of social signals of emotion (Tost et al., 2010; Peltola et al., 2014) to an observed and self-reported degree of empathetic reactions to the emotional states of others (Bakermans-Kranenburg \& van Ijzendoorn, 2008; Rodrigues, Saslow, Garcia, John, \& Keltner, 2009). In the present study, we wanted to include an analysis of those genetic markers associated with emotional expression and early prosocial behaviour in previous studies. 
Although there are many studies of positive emotion expression or positive affectivity in parentinfant interaction, as far as we know there are fewer studies on positive emotion expression while having simultaneous eye contact. According to Mundy (1995), engaging in eye contact is rewarding to typically developing infants, as it often leads to affectively positive content. Direct eye contact is also associated with higher autonomic arousal, which may indicate a stronger intensity of shared experience in interaction (Kaartinen et al., 2012). We hypothesized that the sharing of a smile or laughter with direct eye contact between a mother and an infant, which we have named shared pleasure (SP), is a marker of high-intensity positive affectivity. Since lower than typical positive affectivity in childhood has been suggested to be an early marker of vulnerability (Olino et al., 2011), we also wanted to study whether SP is associated with resilience, and to determine if it is a simple marker of adequate parent-infant interaction.

To study SP as a phenomenon in early mother-infant interaction, we have utilized video material from a previous study conducted at the University of Tampere (see Puura et al., 2005 for details) and new material. In our first SP study with a sample of 58 two-month-old infants and their mothers (Mäntymaa et al., 2015), we found that infants in dyads with a longer mean duration of SP (SP-MD) showed fewer internalizing and externalizing problems two years later, and that SP also buffered the influence of parental psychopathology on child development. Thus, our previous hypotheses of SP being associated with resilience received some support.

Our specific aim in the present study was to analyse in more detail which maternal and - in particular - infant characteristics contribute to the occurrence and longer duration of SP sequences in parent-infant interaction. The characteristics hypothesized to be related to SP included maternal behaviours associated with good parent-infant interaction (i.e. high parental sensitivity and structuring), and factors associated with high maternal sensitivity, such as non-depressed maternal mood and the mother's perception of low stress despite recent stressful life events. From the infants' side, we hypothesized that characteristics associated in previous studies with expressed positive emotions in interaction with the mother - such as high infant responsiveness to parental bids, the high involvement of the parent, positive infant temperament, female gender, and a lack of infant social withdrawal - would be associated with more SP. We also hypothesized that presumably favourable allele variants of genes associated with emotion regulation and social behaviour would be associated with SP. In the final analysis, we tested whether the presumably unfavourable allele variants of the chosen genes and positive and negative affectivity would be plasticity factors, as suggested in differential susceptibility theory (Belsky \& Pluess, 2009). 


\section{METHOD}

\section{Participants and procedure}

The current study was initially designed for assessing infant social cognition and emotion regulation, with the sample size planned to be 120 mother-infant dyads. A recruitment letter along with an opt-in/ out postcard was sent to all parents of infants born in the Tampere city area (i.e., within 10-15 km of the city centre) who fitted the age range of the proposed study, i.e. the infants were $<5$ months at the time of recruitment. The names and birth dates of the children and the addresses of the potential participants were obtained from the Finnish Population Information System. The participants of the study were the first 120 mothers volunteering to participate in the study who met the inclusion criteria. Recordings of mother-infant interaction were obtained from 113 mother-infant dyads (94\% of the initial sample). For 109 of them, study questionnaires were available, and for 96 of them, infant genetic data were available. Complete datasets were available for 94 dyads. For the remainder, the data were missing at random. The study was approved by the Ethics Committee of Pirkanmaa Hospital District.

Parents who indicated their interest in the study by responding to the recruitment letter with the opt-in postcard were called to confirm their interest in participating. During the telephone conversation, a pre-screening consisting of yes/no questions was conducted in order to ascertain whether the infant met the inclusion criteria for the study, i.e. full-term birth between 37 and 42 weeks' gestational age, birth weight $>2500 \mathrm{~g}$, and no history of visual or neurological abnormalities. The purpose of the study and the methods used for collecting the data were explained to the participants who met the inclusion criteria. After answering any of the parent's questions and following the parent's decision to participate, the researcher scheduled an appointment and sent appropriate instructions regarding the laboratory visit for the neurocognitive testing of the infant at 5 and 7 months of age (Forssman et al., 2014; Peltola, Forssman, Puura, van Ijzendoorn, \& Leppänen, 2015; Yrttiaho, Forssman, Kaatiala, \& Leppänen, 2014). Written, informed consent was obtained during the first visit.

To collect background information and control for potential confounding variables, e.g. postnatal neurological problems, the parents were given a set of questionnaires at the end of the infant neurocognitive testing visit. Parents were asked to fill out the questionnaires at home and return them in a pre-paid envelope. The questionnaires included 1) a general infant health and life events inventory for the mothers, 2) the Edinburgh Postnatal Depression Scale for assessing current depressive symptoms in mothers (Cox, Holden, \& Sagovsky, 1987), and 3) the Infant Behavior Questionnaire for assessing infant temperament (Rothbart, 1981). Mothers were also asked to make an appointment 
at the Laboratory Centre of Tampere University Hospital, where a single blood sample (3.0 ml EDTAwhole blood) was taken from the infants by an experienced laboratory nurse. The samples were stored in a freezer at $-20^{\circ} \mathrm{C}$.

For the purposes of examining maternal and infant interactive behaviour, a research assistant visited the mothers at their home within two weeks of the laboratory visit at 7 months and videotaped 15 minutes of free play between the mother and infant. The mothers were instructed to play with their infant in the same manner as they usually would. No further instructions were given to the mothers about the use of toys or how to interact with the infant. In an unstructured situation, we hoped that the dyadic interaction would be as natural as possible even in the presence of a research assistant and camera, and thus represent the way each dyad would engage in SP. The research assistant was instructed not to interfere with the interaction of the dyad, but to try to keep the faces of both the mother and infant in the frame at the same time as much as possible.

All 113 videos were first coded for SP, then after several months' break for the parentinfant interaction, and finally - again after several months' break between the codings - for the possible symptoms of the infant's withdrawal from social interaction.

\section{Measures}

SP in parent-infant interaction was analysed from the first 5 minutes of the recorded play interaction. SP in parent-infant interaction was defined as the parent and the child sharing positive affects in synchrony. This had to be expressed in a facial expression as the curving of the mouth into a smile or laugh with gaze contact and a simultaneous or synchronized beginning and ending. Tapes were first observed at full speed, and all possible sequences of SP were sought and tagged. The tagged parts of the videotapes were then reviewed at half-speed, and the beginnings and endings of the SP sequences were registered second by second. To assess interrater reliability, 15 videos (13\%) were rated by two independent coders. The kappas regarding the SP variables used in the analysis - i.e. the occurrence of SP sequences and the mean duration of SP $(<0.5$ or $>0.5 \mathrm{~s})$ - were 0.91 and 0.43 . The respective rates of interrater agreement were $96 \%$ and $83 \%$. These rates may be regarded as strong and satisfactory, respectively (Healey, 2012; Altman, 1999). The mother and infant's interaction behaviour was analysed from the remaining 10 minutes of the videotapes with the Emotional Availability Scales, $4^{\text {th }}$ edition (EAS; Biringen, 2008) for 1) parental sensitivity (i.e. ability to notice and respond to the child's needs, expressed emotional warmth in the interaction), 2) parental structuring (i.e. ability to help the child function well in the situation), 3) child responsivity (i.e. the child's response to parental cues), and 4) the child's involvement with the parent (i.e. willingness to engage the parent in interaction). Each scale is rated from 1 to 7 , with higher scores indicating more 
optimal behaviour. In the scales, scores of 5 or higher indicate the absence of problems, and scores of 4 or lower indicate problems in the assessed behaviour. All tapes were analysed by a certified coder (KP) trained in the use of the methods and whose interrater reliability for the EAS scales tested against an independent coder (MM) using 20 videotapes was high (ICC 0.98 for sensitivity, 0.95 for structuring, 0.90 for child responsiveness, and 0.97 for child involvement).

The Edinburgh Postnatal Depression Scale (EPDS; Cox et al., 1987) is a self-report questionnaire originally designed for screening depression among women during the postpartum period, but it has also been found to have satisfactory validity among non-postnatal women (Cox, Chapman, Murray, \& Jones, 1996). The EPDS scale consists of 10 items in which mothers are asked to choose from the options that best describe their feelings during the previous seven days. Each item is scored on a four-step scale from 0 to 3, the maximum score of 30 indicating a high level of depressive symptoms. Scores of 13 or more indicate possible depression, though in some studies a lower cut-off of 9/10 is also used to indicate depression. The EPDS has been validated for Finnish population by Kangasmäki-Nummenmaa (1989) and Tamminen (1990). The Cronbach alpha, calculated from a Finnish sample of 243 mothers with 6-month-old infants (Tamminen, 1990), for the EPDS was 0.89, indicating good consistency of the method in the relevant Finnish population.

The Recent Life Events Questionnaire (Brugha, Bebington, Tennant, \& Hurry, 1985) is a 19-item self-report on the occurrence and effect of stressful life events during past 12 months. The respondent answers whether he/she has had such a life event (no $=0$, yes $=1$ ), and whether the respondent thinks it is still affecting him/her (no $=0$, yes $=1)$. The scores are summed, with a higher score indicating more stressful events and a stronger effect.

The Infant Behavior Questionnaire (IBQ; Rothbart, 1981) is a parental report designed to assess the temperamental characteristics of 3- to 12-month-old infants, with 90 items scored from 0 (does not apply) to 7 (most definitely applies) and describing infant behaviour in everyday situations, such as nappy changes, feeding, and dressing. The items form six subscales: Activity Level, Smiling and Laughter, Distress and Latency to Approach Novel Stimuli (Fearfulness), Distress to Limitations, Soothability, and Duration of Orienting. In a previous study with a Finnish sample of 231 mother-infant/child dyads the Cronbach alphas for the subscales ranged from 0.74 to 0.93 (Komsi et al., 2006). In this study, Positive Affectivity is the calculated mean of the scores for Activity Level, Smiling and Laughter, and Soothability, and Negative Affectivity is the mean of the scores for both distress variables. According to the differential susceptibility hypothesis (Belsky \& Pluess, 2009), negative affectivity is regarded as a potential plasticity factor, and the differential susceptibility hypothesis was tested for this marker. 
The symptoms of the infant's withdrawal from social interaction were analysed from the videotapes with the Alarm Distress Baby Scale (ADBB; Guedeney \& Fermanian, 2001). The ADBB was designed to detect signs of sustained infant social withdrawal that appears as a result of prolonged stress. It consists of 8 items concerning the behaviour and features of the baby. For each item, a score of 0 represents the best functioning or normality of the infant and a score of 4 represents severe abnormality. A total score of 5 or higher is considered deviant and a sign of infant distress (Guedeney \& Fermanian, 2001; Puura et al., 2007). The rating can be done immediately after observation in a live situation or from a videotape recording. The ADBB ratings were done using the whole 15-minute sequence by one of the authors (KP), whose interrater reliability was tested against an independent coder (OI) trained in the method with 20 tapes (ICC 0.95 for total score).

\section{Genotyping of the infants}

Blood samples were analysed for the following genetic markers: 1) STPP, rs3813034; 2) TPH2 SNP, rs4570625 (-703 G/T); 3) HTR1A-1019, rs6295; and 4) OXTR, rs53576. According to earlier research, the favourable variants were hypothesized to be 1) TT (not carrying G) for STPP, 2) GG (not carrying T) for TPH2 -703, 3) GG (not carrying C) for HTR1A-1019, and 4) GG (not carrying A) for OXTR. However, when considering that the genetic variants may be plasticity factors rather than vulnerability factors (Belsky \& Pluess, 2009), the differential susceptibility hypotheses were tested for each genetic marker in the preliminary analysis. Genomic DNA was extracted from peripheral blood leukocytes by using a QIAamp DNA Blood Minikit and automated biorobot M48 extraction (Qiagen, Hilden, Germany). Genotyping was performed by using Taqman SNP Genotyping Assays and an ABI Prism 7900HT Sequence Detection System (Applied Biosystems, Foster City, CA, USA). No discrepancies were detected in the genotyping results of duplicate samples.

\section{Statistical methods}

Two separate outcome variables, occurrence and longer mean duration of SP sequences (SP-MD), were examined. Preliminary analysis showed that SP-MD was correlated with the total duration of SP (Spearman $\rho=0.67)$, the shortest duration $(\rho=0.54)$, and the longest duration $(\rho=0.93)$, so it could be chosen to represent the duration of SP in further analysis.

SP occurrence was dichotomized as yes/no. Regarding the SP sequence length, technical limitations caused the beginning and end time of very short SP sequences to be the same. In such cases, the duration of the SP sequence was set at 0.5 seconds. SP-MD for each dyad was then 
calculated as the arithmetic mean of all their sequences. Based on our previous study (Mäntymaa et al., 2015), SP-MD was dichotomized at its lower quartile as $\leq 0.5 \mathrm{~s} />0.5 \mathrm{~s}$.

The maternal and infant characteristics used as explanatory variables are listed in Tables 1 and 2. The dichotomization of categorized variables used to focus on differences between pathological and normal groups was based either on established cut-off points (EAS and ADBB), on the results of preliminary frequency and cross tabulation analyses (maternal stressful life events and their effect), or, in case of the gene variables, on presumed favourable/non-favourable allele combinations. The EPDS score was used as a continuous variable because of the small number of mothers scoring above the EPDS cut-off point. No established cut-off points exist for IBQ scores.

The associations of each of the explanatory variables with both outcome variables were first examined pairwise for the entire sample as well as separately for mother-son and mother-daughter dyads. For comparisons of dichotomized variables, cross-tabulations with Fisher's exact test were used. When one of the variables was continuous, the Mann-Whitney U test was used because some of the variables were non-normally distributed.

The possibility of differential susceptibility (Belsky \& Pluess, 2009) was examined. The susceptibility factors considered were the four genetic markers mentioned above and infant negative affectivity, while the environment factors examined were EPDS, maternal sensitivity, structuring, and maternal life events affecting the mother. Preliminary analyses were conducted to test the susceptibility factor prerequisites: independence of the potential susceptibility factor and 1) the outcome, 2) the environment factors, and 3) the comparison of the outcome values in the groups defined by the dichotomized categories of the potential susceptibility factor and the environment factor under consideration (those with a susceptibility factor and without an environment factor having the largest outcome value and those with both a susceptibility and environment factor having the smallest value). As no evidence of differential susceptibility was seen in any combination, these results are not reported. Finally, to take into account the simultaneous effect of explanatory variables and to find those with the strongest effect, one backward stepwise logistic regression per outcome variable was performed. The explanatory variables that pairwise showed a statistically significant $(p$ $<0.05)$ or an indicative $(0.05<p<0.10)$ association for either or both sexes were entered into the models, together with sex as a potential confounder. The EPDS score was square root-transformed before being entered into the models, as its distribution was highly skewed.

Categorized variables are described as percentages. Because some of the continuous variables had non-normal distributions, the medians and quartiles are primarily reported, but for descriptive purposes means and standard deviations (SD) are shown. The results are reported separately by sex only when there were statistically significant differences between them. All 
analyses, except differential susceptibility, were performed 1) using all cases with non-missing values for the variables involved in each particular analysis $(n=96-113)$ and 2$)$ using only cases with nonmissing values in all variables involved $(n=94)$. As the results were essentially the same for both case selection methods, only those for the first method are reported. $P$-values $<0.05$ were regarded as significant. However, values up to 0.10 are reported, because in a rather small sample and with some rather small group sizes after dichotomization, such a $p$-value can indicate a true difference that would be significant in a larger sample. The analyses were performed with SPSS 23.

\section{RESULTS}

The description of the sample is given in Table 1. The infants were on average 7 months old (SD 4 days), and there was a slight predominance of boys $(n=65,57.5 \%)$. Descriptives of the EPDS and IBQ scores used as continuous variables are shown in Table 1. The characteristics of the categorized variables used in the analyses, indicating the categories applied when dichotomized, are shown in Table 2.

$===$ Tables 1 and 2 around here $==$

\section{SP in mother-infant interaction}

No sex differences were found in the occurrence of SPs or in SP-MD in this sample. The frequency of SP sequences in the dyads $(n=113)$ varied considerably (Table 1$)$. There were 33 dyads $(29 \%)$ with no SP sequences during the 5-minute free play interaction. For those dyads that had at least one SP sequence ( $n=80$ ), considerable variability was found in SP-MD (Table 1 ). In three quarters of the dyads, the SP-MD was longer than 0.5 seconds (Table 2).

$===$ Table 3 around here $==$

\section{Maternal characteristics and SP}

Two thirds of the mothers scored five or more in maternal sensitivity (Table 2). Better maternal sensitivity was associated with the occurrence of SP for both boys and girls (Figure 1). Sixty per cent of the mothers scored five or more in maternal structuring. Better maternal structuring was associated with longer SP-MD for both boys and girls (Figure 2).

Only five mothers scored above the higher cut-off point in EPDS, indicating depression, while 13 mothers scored above the lower cut-off point; the median score was 5 (Table 1). The 
maternal depressive symptoms score was associated with SP only for boys (see below in Sex differences and SP). In this sample, 73\% of the mothers had experienced one or more stressful life events during the 12 months prior to the study (Table 2). Life events were not associated with SP. Some $47 \%$ of the mothers with a negative life event reported that it still had an effect on them, and the association with the occurrence of SP sequences was indicative in mother-son dyads (Figure 1).

$===$ Figures 1 and 2 around here $==$

\section{Infant characteristics and SP}

In the EAS, $65 \%$ of the infants scored five or more in child responsiveness and $60 \%$ scored five or more in child involvement (Table 2). Child responsiveness in interaction was associated with the occurrence of SP sequences (Figure 1). Boys and girls did not differ in temperament, as examined through IBQ scores for positive and negative affectivity (Table 1). There was a sex difference in the association of negative affectivity and SP (see below).

Two thirds of the infants scored below the cut-off point of 5 in the ADBB, indicating no signs of social withdrawal. There was a significant difference between boys and girls in the median score of the ADBB, with boys scoring higher. There was also a sex difference in the association of ADBB score and SP (see below).

\section{Sex differences in SP}

Some sex differences emerged in both maternal and infant characteristics associated with SP. For boys, a higher maternal depressive symptoms score was associated with the occurrence of SP (Table 3), and a lower maternal depressive symptoms score with longer SP-MD (Table 3). For boys, maternal sensitivity was also associated with longer SP-MD (Figure 2). Of the infant characteristics, higher child responsiveness and longer SP-MD were associated for boys (Figure 2). Longer SP-MD was also significantly more common in the group of boys scoring five or more in the ADBB (Figure 2).

For girls, better maternal structuring, greater child involvement, and scoring below five in the ADBB were associated with the occurrence of SP (Figure 1). For girls, infant negative affectivity was also associated with the occurrence of SP (Table 3).

\section{Genetic markers and SP}

Of the four candidate genes chosen for the analyses - 1) STPP, rs3813034; 2) TPH2 SNP rs4570625 (-703 G/T); 3) HTR1A-1019, rs6295; and 4) OXTR, rs53576 - only TPH2-703, rs4570625 and 
HTR1A-1019, rs6295 were statistically significantly associated with the occurrence of SP sequences; their data are reported below.

TPH2 SNP rs4570625 (-703 G/T) was statistically significantly associated with the occurrence of SP in boys (Figure 1). In the entire sample, the proportion of dyads with at least one SP sequence in the group with the GG allele genotype was $80 \%$, compared to $53 \%$ in the group with the GT or TT allele genotype ( $p=0.006)$. There was no association with SP-MD.

HTR1A-1019, rs6295, dichotomized as shown in Table 1, was indicatively associated with the occurrence of SP sequences in mother-son dyads ( $p=0.097$, Figure 1$)$. In the entire group, the proportion of dyads with at least one SP sequence was 50\% in the CC allele genotype group and 77\% in the group having either the CG or GG allele genotype ( $p=0.013$ ). There was no association with SP-MD.

\section{Combined characteristics and SP}

When the simultaneous effect of variables showing a pairwise association with the occurrence of SP sequences was examined with a backward stepwise logistic regression, it was noted that a higher maternal depressive symptoms score, better infant responsiveness in interaction, and the favourable TPH2 SNP rs4570625 (-703 G/T) genotype of the infant independently contributed to the occurrence of SP sequences (Table 4). When similarly predicting a longer duration of SP sequences, better maternal structuring, a lower maternal depressive symptoms score, and infant involvement in interaction were independent contributors (Table 4).

\section{DISCUSSION}

This was our second study exploring dyadic, shared positive affectivity - which we refer to as SP in parent-infant interaction. Although the current sample was initially recruited for a study on infant social cognition, it allowed us to investigate the possible connections between those maternal and infant characteristics that might have an impact on SP. According to our results, some maternal and infant characteristics were independently associated with both the occurrence and duration of SP.

Previously Feldman (Feldman, Greenbaum, \& Yirmiya, 1999; Feldman, 2003; 2007) has emphasized the importance of sharing positive affects in parent-infant interaction, and further claimed that synchronized positive affects in parent-infant interaction increase the infant's relatedness and are essential for the development of self-regulation. Our criteria for SP were stricter than in previous studies on positive affectivity or positive emotional expressions in parent-infant 
interaction (e.g. Olino et al., 2011; Davis \& Suveg, 2014), since they included simultaneous eye contact and mutually positive emotional expression.

Through previous literature, we know that after the first two months of life, the gaze becomes the central mode of interpersonal relatedness, and gaze synchrony becomes the main vehicle for social interactions (Wright, 1991). We chose to include eye contact in the criteria, as we wanted to code those moments where we could be sure that both the parent and infant were sharing positive affects at the same time. We also thought that this would lead to a more intensive positive emotional experience for the infant, based on earlier studies with older children where direct eye contact has been connected to stronger emotional valence (Kaartinen et al. 2012). Interestingly, Leong et al. (2017) recently demonstrated that a direct gaze resulted in stronger bidirectional adult-infant neural connectivity.

At least in theory, direct eye contact between a parent and infant while sharing a positive affect could mean a stronger emotional experience for both. It could perhaps be one of the experiences needed for an infant to develop a full capacity for positive emotionality. High positive emotional intensity has also been associated with emotion regulation difficulties and is likely to require a greater regulation effort (Suveg et al., 2010). It will be interesting to see in the follow-up assessments of the sample whether SP in mother-infant dyads is associated with better social and emotional development in the child.

The infants in this study were 7 months old, and interestingly the average number of SP sequences was slightly less and the MD-SP somewhat shorter than in our previous study with 8- to 11-week-old infants (Mäntymaa et al., 2015). The younger infants sat in a baby chair facing their mother, whereas the 7-month-old infants in the current study were able to crawl, and thus spontaneous opportunities for eye contact may have occurred less frequently. Some of the SP sequences were no doubt inevitably lost in the current study, as on some occasions the coder was unable to see the face of the infant and the mother simultaneously. It is also possible that the reduced SP is a genuine phenomenon and related to progressing emotional development. Previously, the amount of positive emotional expressions in interaction has been shown to decline after the age of 19 months (Sallquist et al., 2010). Since we coded only positive emotional expressions with direct eye contact, it is also possible that SP may become more intentional from the infants' side, and the mother's smiles are not as automatically responded to at 7 months as they are at 2 months.

Previous research has linked child positive affectivity to both positive and negative outcomes, and in their review, Davis and Suveg (2014) suggest that it might moderate the relationships between contextual factors and indices of child adjustment and maladjustment. A link between low levels or a lack of child positive affectivity and an increased risk for later depression has 
emerged in many studies, particularly in families where parents have depressive disorders (Olino et al., 2011; Granat et al., 2017). In our study, 29\% of the mother-infant dyads did not have SP in the five-minute time period. The current research team will be conducting follow-up assessments with the sample at the ages of two and five years to better understand the impact of these patterns on child outcome.

In line with several previous studies showing the association of parental sensitivity with positive affectivity in parent-child interaction (e.g. Kochanska, Friesenborg, Lange, \& Martel, 2004; Kivijärvi, Räihä, Kaljonen, Tamminen, \& Piha, 2005), higher maternal sensitivity was associated with the occurrence of SP. However, sensitivity did not fit into the final model of maternal and infant characteristics independently associated with SP. Maternal structuring was independently associated with a longer duration of SP, and was thus left in the final model. Structuring in dyadic interaction as defined in the EAS manual means the degree to which the adult appropriately structures the child's play and the child accepts the adult's bids to structure (Biringen, 2008). Longer SP was seen in dyads where the mother was able to create opportunities for eye contact and a shared joyful expression, with the infant joining in. According to our findings, structuring could be another important parental characteristic that should be assessed and supported in order to provide longer lasting shared positive emotional experiences for the infant (Mäntymaa et al., 2015).

Since the sample was a population-based volunteer sample, the majority of the mothers participating in the study had few or no symptoms of depression. Maternal depressive symptoms had a similar association with both the occurrence and duration of SP in both the pairwise analysis and the final regression, which we discuss below.

Though stressful life events have in previous studies been associated with poorer parentinfant interaction (Tein et al., 2000; Choe et al., 2013) and lower child positive affectivity (Pesonen et al., 2008), recent stressful life events reported by the mothers had no association with SP in this sample. It is possible that psychologically stressful conditions may not have affected the mothers' ability to experience and express positive emotions with their infants (Folkman \& Moskowitz, 2000).

Infant temperament was measured with the maternal report of infant positive and negative affectivity, and in this sample the infants scored more highly for positive affectivity (Rothbart, 1981). In contrast to the previous studies of, e.g. Else-Quest et al. (2006) and Schore (2017), we found no sex difference in measured infant temperament, and infant temperament had no independent association with SP in the whole sample. However, there were some sex differences in the association between infant temperament and SP.

As expected, the majority of infants in the sample did not show symptoms of infant social withdrawal in the ADBB. Nevertheless, the proportion of infants scoring above the cut-off point was 
remarkably higher than in normal population studies (Puura et al., 2010; Guedeney, Matthey, \& Puura, 2013). The volunteer sample may have included more mothers with some kind of problems with their infants compared to a normal population sample. Infant social withdrawal was associated with SP in different ways for boys and girls.

There were some sex differences in our findings. In our sample, mothers were more sensitive in interactions with girls than with boys. Similar findings of mothers displaying more sensitivity towards girls than boys have been reported with both younger (Schore, 2017) and older children (Paavola, Kemppinen, Kumpulainen, Moilanen, \& Ebeling, 2006; Tamis-LeMonda et al., 2009). A sex difference was also found for symptoms of infant social withdrawal, with boys showing more symptoms than girls. In previous studies, boys have been found to prefer dyadic interaction and to make eye contact less often than girls (Benenson, 1993; Lutchmaya, Baron-Cohen, \& Raggatt, 2002), which may partly explain our findings. On the other hand, our findings are in line with studies suggesting that infant boys may be experiencing less sensitive parent-infant interaction, and that they may also be more vulnerable to sub-optimal parenting (Schore, 2017).

For boys, better maternal structuring and higher infant responsiveness and involvement were associated with longer SP, but the same was not true for girls. Tronick (2007) has stated that boys are more demanding partners in interaction than girls, and they may need more of their mother's support. Our findings fit with Tronick's idea that boys may be less likely to experience longer SP in interaction with their mothers if they are less active in the interaction themselves and their mothers similarly are less able to support them in the interaction.

Infant negative affectivity and a lack of social withdrawal were associated with more SP for girls, but not for boys. Previously, it has been found that infant girls are more attracted to human faces (Lutchmaya \& Baron-Cohen, 2002) and smiled more at their mothers than boys (Cossette et al., 1996). It has also been suggested that mothers have fewer difficulties in tolerating negative affectivity in their infant girls, as girls display less intensive negative reactions (Schore, 2017).

Our hypothesis of the possible association between SP and the functional polymorphism of certain genes included in the serotonin functions of the brain was partially supported. In one of our previous studies (Leppänen et al., 2011), relative to TPH2 -703 G/G homozygotes, carriers of the TPH2 -703 T allele exhibited a higher number of missing attention shifts, especially in the context of happy and fearful facial expressions, suggesting that variation in serotonin modulates those early emerging attentional systems that are foundational for the development of more advanced emotional and behavioural capabilities. In the current study, the G allele of TPH2 -703 was significantly associated with the occurrence of SP, and in the final regression model the GG genotype of TPH2 703 predicted having at least one SP moment in mother-infant interaction. Our results indicate the 
possibility that the GG allele variant previously associated with lower risk for depression (Gao et al., 2012) may also play a role in positive emotional development, fitting the transactional model of child positive affects suggested by Davis and Suveg (2014). However, in a recent study, the TT genotype was associated with more a favourable outcome by young adulthood, especially in males (Laas et al., 2017). Further studies are needed, as the role of genes in child psychological development has proven to be quite complex.

Regarding differential susceptibility, we also looked at whether infant positive and negative affectivity and the allele variants of the analysed genes could be susceptibility factors for SP. Having a challenging temperament or a proposedly unfavourable allele variant of the genes analysed in this study did not affect the SP in either negative (low maternal sensitivity) or positive (high maternal sensitivity) environmental experiences (Belsky, Bakermans-Kranenburg, \& Van Ijzendoorn, 2007).

In the final analyses, the maternal EPDS score had a two-way independent effect on SP in interaction. A higher maternal depressive symptom score was associated with more frequent SP. It is possible that some of the mothers scoring higher in the EPDS also experienced above-average anxiety. A recent study (Moore, Quigley, Voegtlin, \& Dipietro, 2015) found that anxious mothers smiled more at their infants than depressed and non-anxious mothers, and it is possible that infants might start to respond to maternal smiles, resulting in more frequent but shorter SP (Kaye \& Fogel, 1980; Moore et al., 2015). On the other hand, a higher maternal depressive symptom score was associated with shorter SP-MD. Mothers with depressive symptoms may have been poorer in synchronizing or structuring the interaction (Feldman, Granat, \& Gilboa-Schechtman, 2005), and the emotional experience for the infant may not have been optimal. This possibility is supported by our previous study, where only longer SP-MD was associated with better child outcome (Mäntymaa et al., 2015). That maternal structuring contributed independently to SP-MD was a slightly unexpected finding. Being able to engage the infant in interaction where SP is possible often requires the structuring of the infant's posture, and also the initiation of playful interaction.

The association of infant responsiveness with SP is quite logical, as it represents the ease with which the infant accepts and responds to parental bids - in this study, the mothers' positive emotional expressions. In the EAS, involvement means the degree to which the child is interested in involving the adult in his or her activities, which also means turning and looking towards the adult (Biringen, 2008). Actively involved infants have most likely stayed in eye contact for a longer time and thus been given the opportunity for the longer sharing of positive emotional expressions.

This study has some strengths and limitations. The study was initially designed for experimental research on the development of infant social cognition. Therefore, both the material and methods were not optimal for the current study of SP in interaction. For example, using the existing 
video material did not allow for the analysis of parent-infant interaction in different situations. However, using data from an already existing study can also be seen as an economical and ethical choice, as it only required the reanalysis of existing data for the additional aspect of parent-infant interaction.

The EAS used in the study for assessing parent-infant interaction has been widely validated, as has the ADBB. The criterion of SP was created by the authors, and it has only been used in our own studies and in one study in South Africa with a high-risk population (Lachman et al., 2016). The fact that the video recordings were analysed with three different methods may have caused measurement bias. However, this is unlikely, as there was a break of several months between each of the analyses. Furthermore, the methods also differ from one another: EAS is a global method for assessing parent-infant interaction, the ADBB is a highly structured observation method that measures only signs of social withdrawal, and SP is the mechanical counting and measuring of strictly defined shared positive emotional expressions. Interrater reliability was also checked for all three methods between the main coder and an independent coder, and it was good for each method.

The method for assessing SP from the videotapes was quite crude, but since the videos were of a free play situation with the mother and infant being seen from changing angles, it was not possible to use any computerised analysis method. The five-minute sequence may seem short for the reliable assessment of SP, but in many studies of positive emotionality in parent-infant interaction, the analysed sequences have been as short or even shorter (e.g. Sallquist et al., 2010). It has also been shown that a short, five-minute sequence of parent-infant interaction correlated surprisingly well with one-year observation results (Kemppinen et al., 2005).

The limitations of the study include the relatively small sample. The results should be interpreted with caution, particularly the genetic analysis. However, the analyses focused on a limited number of candidate gene variants for which there is prior evidence of a functional genetic polymorphism associated with emotion-related brain function, and the minor allele frequency was large enough to allow for analyses in the current sample. Another limitation is that due to lack of resources, we were not able to genotype the mothers, only the infants.

\section{Conclusions}

In the present study, our specific aim was to analyse in more detail which maternal and infant characteristics contribute to the occurrence and longer duration of SP sequences in parent-infant interaction. Based on our findings, those dyads where the mother and infant were best able to read each other's positive cues and to respond to them were more likely to experience mutual positive affects, as seen in SP. In that sense, our hypothesis of SP being a possible marker of adequate parent- 
infant interaction received some support. Of the infant characteristics, the GG variant of TPH2 -307, which has previously been linked to a lower risk for depression, was associated with SP. The functional polymorphism of this gene might thus play some part in the development of positive emotionality and the infant's capacity to participate in shared pleasure in parent-infant interaction. The infants in the study sample are being followed-up until school age, and it will be interesting to see whether the findings concerning SP in early mother-infant interaction are connected to further socio-emotional development.

\section{REFERENCES}

Abidin, R.R. (1992). The determinants of parenting behavior. Journal of Clinical Child Psychology. 21, 407-412. doi: 10.1207/s15374424jccp2104_12.

Aksan, N.,,Goldsmith, H. H.,Smider, N.A., Essex, M J., Clark, R., Hyde, J.S., Klein, M. H.,Vandell, D. L. (1999). Derivation and prediction of temperamental types among preschoolers. Developmental Psychology, 35(4), 958-971.

Altman, D.G. (1999). Practical statistics for medical research. Chapman \& Hall/CRC, London.

Bakermans-Kranenburg, M.J., \& Van Ijzendoorn, M. H. (2008). Oxytocin receptor (OXTR) and serotonin transporter (5-HTT) genes associated with observed parenting. Social Cognitive \& Affective Neuroscience, 3, 128-134.

Belsky, J., Bakermans-Kranenburg, M. J., \& van IJzendoorn, M. H. (2007). For better and for worse: Differential Susceptibility to environmental influences. Current Directions in Psychological Science, 16(6), 300-304.

Belsky, J., \& Pluess, M. (2009). Beyond diathesis stress: Differential susceptibility to environmental influences. Psychological Bulletin, 135(6), 885-908.

Benenson, J. F. (1993), Greater Preference among Females Than Males for Dyadic Interaction in Early Childhood. Child Development, 64, 544-555. doi:10.1111/j.14678624.1993.tb02927.x

Biringen, Z. (2000). Emotional availability: Conceptualization and research findings. American Journal of Orthopsychiatry, 70, 104-114.

Biringen, Z. (2008). The Emotional Availability (EA) Scales, 4th edition. Published by emotionalavailability.com, PO Box, 3625, Boulder, Colorado 80307.

Blehar, M., Lieberman, A., \& Mary D. Salter Ainsworth. (1977). Early Face-to-Face Interaction and Its Relation to Later Infant-Mother Attachment. Child Development, 48(1), 182-194. doi:10.2307/1128897

Bøe, T., Sivertsen, B., Heiervang, E., Goodman, R., Lundervold, A.J., Hysing, M. (2014). Socioeconomic status and child mental health: the role of parental emotional well-being 
and parenting practices. Journal of Abnormal Child Psychology, 42(5), 705-15. doi: 10.1007/s10802-013-9818-9.

Bonanno, G.A. (2004). Loss, trauma, and human resilience: Have we underestimated the human capacity to thrive after extremely aversive events? American Psychologist, 59, 20-28.

Bornstein, M. H. and Tamis-LeMonda, C. S. (1989), Maternal responsiveness and cognitive development in children. New Directions for Child and Adolescent Development, 1989: 49-61. doi:10.1002/cd.23219894306

Brugha, T., Bebington, P., Tennant, C. \& Hurry, J. (1985). The list of threatening experiences: A subset of 12 life events categories with considerable long-term contextual threat. Psychological Medicine, 15, 189-194.

Campbell, S.B. (1994) Journal of Abnormal Child Psychology, 22: 147-166. https://doi.org/10.1007/BF02167897

Campbell, S. B., Cohn, J. F., \& Meyers, T. (1995). Depression in first-time mothers: Mother-infant interaction and depression chronicity. Developmental Psychology, 31(3), 349-357. http://dx.doi.org/10.1037/0012-1649.31.3.349

Carver, C. S., Johnson, S. L., \& Joormann, J. (2008). Serotonergic function, two-mode models of self-regulation, and vulnerability to depression: What depression has in common with impulsive aggression. Psychological Bulletin, 134(6), 912-943. http://dx.doi.org/10.1037/a0013740

Caspi, A., Sugden, K., Moffitt, T.E.,Taylor, A., Craig, I.W., Harrington, H.L., McClay, J., Mill, J., Martin, J., Braithwaite, A., Poulton, R. (2003). Influence of Life Stress on Depression: Moderation by a Polymorphism in the 5-HTT Gene. Science, 301, 5631, 386-389.

Choe, D., Olson, S., \& Sameroff, A. (2013). Effects of early maternal distress and parenting on the development of children's self-regulation and externalizing behavior. Development and Psychopathology, 25(2), 437-453. doi:10.1017/S0954579412001162

Cohn, J., Tronick, E. (1989).Specificity of Infants' Response to Mothers' Affective Behavior. Journal of the American Academy of Child \& Adolescent Psychiatry, 28 (2), 242-248 https://doi.org/10.1097/00004583-198903000-00016.

Cole, P.M., Michel, M.K., \& Teti, L.O. (1994). The development of emotion regulation and dysregulation: A clinical perspective. Monographs of the Society for Research in Child Development, 59(2-3), 73-100.

Cossette, L., Pomerleau, A., Malcuit, G. et al. (1996). Emotional expressions of female and male infants in a social and a nonsocial context. Sex Roles, 35, 693-709. https://doi.org/10.1007/BF01544087

Cox, J.L., Chapman, G., Murray, D. \& Jones. (1996). Validation of the Edinburgh Postnatal Depression Scale. British Journal of Psychiatry, 39 (3), 185- 189. 
Cox, J.L., Holden, J.M., Sagovsky, R. (1987). Detection of postnatal depression. Development of the 10-item Edinburgh Postnatal Depression Scale. British Journal of Psychiatry, 150, 782 6.

Crnic, K.A., Greenberg, M.T., Ragozin, A.S, Robinson, N.M., Basham, R.B. (1983). Effects of Stress and Social Support on Mothers and Premature and Full-Term Infants. Child Development , 54,(1), 209-217.

Curley, J.P., Keverne, E.B. (2005). Genes, brains and mammalian social bonds. Trends in ecology and evolution 20, 561-567.

Darwin, C. (1872). The expression of the emotions in man and animals. London: Murray. Library Level 12 Sp Coll 652 and Library Research Annexe Store Stone 763.

Davis M., Suveg, C. (2014). Focusing on the Positive: A Review of the Role of Child Positive Affect in Developmental Psychopathology. Clinical Child and Family Psychology Review, 17, 97-124.DOI 10.1007/s10567-013-0162-y.

Denham, S. A., Lehman, E. B., Moser, M. H., \& Reeves, S. L. (1995). Continuity and change in emotional components of infant temperament. Child Study Journal, 25(4), 289-308.

Dockray, S., \& Steptoe, A. (2010). Positive affect and psychobiological processes. Neuroscience \& Biobehavioral Reviews, 35, 69-75.

Dolan, R.J. (2002). Emotion, cognition, and behavior. Science, 298, 1191-1194.

Dyb, G., Jensen, T.K., Nygaard, E. (2011). Children's and parents’ posttraumatic stress reactions after the 2004 tsunami. Clinical Child Psychology and Psychiatry 16, (4), 621-634.

Ekman, P. (1972). Universals and cultural differences in facial expressions of emotion. In J. Cole (ed.), Nebraska Symposium on Motivation, 1971. Lincolin, NE: University of Nebraska Press, 207-283.

Else-Quest, N. M., Hyde, J. S., Goldsmith, H. H., \& Van Hulle, C. A. (2006). Gender differences in temperament: A meta-analysis. Psychological Bulletin, 132(1), 33-72. http://dx.doi.org/10.1037/0033-2909.132.1.33

Emde, R,N, (1983). Pre-representational self and its affective core. Psychoanalytic Study of the Child, 38: $165-192$.

Emde, R. N., \& Harmon, R. J. (1972). Endogenous and exogenous smiling systems in early infancy. Journal of the American Academy of Child Psychiatry, 11, 177-200.

Fakra, E., Hyde, L. W., Gorka, A., Fisher, P. M., Muñoz, K. E., Kimak, M., Hariri, A. R. (2009). Effects of HTR1A C(-1019)G on Amygdala Reactivity \& Trait Anxiety. Archives of General Psychiatry, 66(1), 33-40.

Farroni, T., Csibra, G., Simion, F., \& Johnson, M,H. (2002). Proceedings of the National Academy of Sciences of the United States of America, 99(14), 9602-9605, doi:

10.1073/pnas.152159999 
Feldman, R. (2003), Infant-mother and infant-father synchrony: The coregulation of positive arousal. Infant Mental Health Journal, 24, 1-23. doi:10.1002/imhj.10041

Feldman R. (2007). Parent-infant synchrony and the construction of shared timing; physiological precursors, developmental outcomes, and risk conditions. Journal of Child Psychology and Psychiatry, 48:3/4, 329-354. doi:10.1111/j.1469-7610.2006.01701.x

Feldman, R., Greenbaum, C. W., \& Yirmiya, N. (1999). Mother-infant affect synchrony as an antecedent of the emergence of self-control. Developmental Psychology, 35(1), 223-231. http://dx.doi.org/10.1037/0012-1649.35.1.223

Feldman, R., Granat, A., \& Gilboa-Schechtman, E. (2005). Maternal anxiety and depression, mother-infant synchrony, and infant regulation of negative and positive emotions. Paper presented in the biennial meeting of the Society for Research in Child Development, Atlanta, GA.

Field, T. (2010). Postpartum depression effects on early interactions, parenting and safety practices: A review. Infant Behavior \& Development, 33, 1-8. doi:10.1016/j.infbeh.2009.10.005

Field, T., Diego, M., Hernandez-Reif, M., Schanberg,S., Kuhn, C. (2003). Depressed mothers who are "good interaction" partners versus those who are withdrawn or intrusive. Infant Behavior and Development, 26, 238-252.

Field, T., Hernandez-Reif, M., Diego, M. (2006). Intrusive and withdrawn depressive mothers and their infants. Developmental Review, 26,(1), 15-30

Folkman, S., Moskowitz, J. T. (2000). Positive affect and the other side of coping. The American Psychologist 55, 647-654.

Forssman, L., Peltola, M. J., Yrttiaho, S., Puura, K., Mononen, N., Lehtimäki, T., \& Leppänen, J. M. (2014). Regulatory variant of the TPH2 gene and early life stress are associated with heightened attention to social signals of fear in infants. Journal of Child Psychology and Psychiatry, 55, 793-801.

Frankel, K., \& Harmon, R. (1996). Depressed mothers: They don't always look as bad as they feel. Journal of the American Academy of Child \& Adolescent Psychiatry, 35, 289-298.

Fredrickson, B.L. (2004). The broaden-and-build theory of positive emotions. Philosophical transactions of the Royal society of London Series B - Biological sciences, 359(1449), $1367-1377$.

Gao, J., Pan, Z., Jiao, Z., Li, F., Zhao, G., Wei, Q., Pan, F., Evangelou, E. (2012). TPH2 gene polymorphisms and major depression - a meta-analysis. PLoS One. 2012;7(5):e36721. doi: 10.1371/journal.pone.0036721.

Goodman, S.H., Rouse, M.H., Connell, A.M., Broth, M.R., Hall, C.M., \& Heyward, D. (2011). Maternal depression and child psychopathology: A meta-analytic review. Clinical Child and Family Psychology Review, 14, 1-27. doi:10.1007/s10567-010-0080-1 
Granat, A., Gadassi, R., Gilboa-Schechtman, E., \& Feldman, R. (2017). Maternal depression and anxiety, social synchrony, and infant regulation of negative and positive emotions. Emotion, 17(1), 11-27. http://dx.doi.org/10.1037/emo0000204

Guedeney, A., \& Fermanian, J. (2001). A validity and reliability study of assessment and screening for sustained withdrawal reaction in infancy: The alarm distress baby scale. Infant Mental Health Journal, 22(5), 559-575.

Guedeney A, Matthey S, Puura K. (2013). Social withdrawal behavior in infancy: A history of the concept and a review of published studies using the alarm distress baby scale. Infant Mental Health Journal, 34 (6), 516-31.

Gutknecht, L., Waider, J., Kraft, S., Kriegebaum, C., Holtmann, B., Reif, A., Schmitt, A., Lesch, K.-P.. (2008). Deficiency of brain 5-HT synthesis but serotonergic neuron formation in Tph2 knockout mice. Journal of Neural Transmission, 115, 1127-1132.

Hartley, C.A., McKenna, M.C., Salman, R., Holmes, A., Casey, B.J., Phelps, E.A., Glatt, C.E. (2012). Serotonin transporter polyadenylation polymorphism modulates the retention of fear extinction memory. Proceedings of the National Academy of Sciences, 109 (14) 54935498; DOI: 10.1073/pnas.1202044109.

Hairiri AR, Holmes A. (2006). Genetics of emotional regulation: the role of the serotonin transporter in neural function. Trends Cognitive Science, 4, 182-191.

Healey, J. F. (2012). Statistics: A tool for social research (9th ed.). Belmont, CA: Wadsworth Cengage Learning.

Kaartinen M, Puura K, Hietanen J, Salmelin R, Helminen M, Himanen S-L. (2012). Autonomic arousal to direct gaze correlates with social impairments among children with ASD. Journal of Autism and Developmental Disorders, 42(9), 1917-27.

Kangasmäki-Nummenmaa, V. (1989). Synnytyksen jälkeinen masennus. Tutkimus EPDSlomakkeen psykometrisistä ominaisuuksista sekä masennukseen liittyvistä tekijöistä. Psykologian laitos, Tampereen yliopisto.

Kaye, K., \& Fogel, A. (1980). The temporal structure of face-to-face communication between mothers and infants. Developmental Psychology, 16(5), 454-464.

http://dx.doi.org/10.1037/0012-1649.16.5.454

Kemppinen, K., Kumpulainen, K., Räsänen, E., Moilanen, I., Ebeling, H., Hiltunen, P. and Kunelius, A. (2005). Mother-child interaction on video compared with infant observation: Is five minutes enough time for assessment?Infant Mental Health Journal, 26, 69-81. doi:10.1002/imhj.20031

Kivijärvi, M., Räihä, H., Kaljonen, A., Tamminen, T., \& Piha, J. (2005). Infant temperament and maternal sensitivity behavior in the first year of life. Scandinavian Journal of Psychology, 46(5), 421-428.Kochanska, G., Friesenborg, A. E., Lange, L. A., \& Martel, M. M. (2004). Parents' personality and infants' temperament as contributors to their emerging relationship. Journal of Personality and Social Psychology, 86(5), 744-759. 
Komsi,N., Räikkönen, K., Pesonen, A.-K., Heinonen, K., Keskivaara, P., Järvenpää, A.-L., Strandberg, T.E.(2006). Continuity of temperament from infancy to middle childhood. Infant Behavior and Development, 29, 494-508.

Laas, K., Kiive, E., Mäestu, J., Vaht, M., Veidebaum, T., Harro, J. (2017) Nice guys: Homozygocity for the TPH2 -703G/T (rs4570625) minor allele promotes low aggressiveness and low anxiety. Journal of Affective Disorders, 215, 230-236.

Lachman A, Niehaus DJH, Puura K. (2016). Shared Pleasure moments in a sample of South African mothers with severe mental illness. Brief oral presentation in the 15th World Congress of the WAIMH, Prague, Czech Republic May 29th -June 2nd, 2016. Published in the Supplement for Infant Mental Health Journal, 37(1),328.

Leong. V., Byrne, E., Clackson, K., Georgieva, S., Lam, S., Wass, S. (2017). Speaker gaze increases information coupling between infant and adult brains. Proceedings of the National Academy of Sciences of the United States of America, 114(50):13290-13295.

Leppänen, J.M., Peltola, M.J., Puura, K., Mäntymaa, M., Mononen, N., Lehtimäki, T. (2011). Serotonin and early cognitive development: variation in the tryptophan hydroxylase 2 gene is associated with visual attention in 7-month-old infants. Journal of Child Psychology and Psychiatry 52, 1144-1152.

Lovejoy, M. C., Graczyk, P. A., O’Hare, E., \& Neuman, G. (2000). Maternal depression and parenting behavior: A meta-analytic review. Clinical Psychology Review, 20, (5), 561-592.

Lutchmaya, S., Baron-Cohen, S. (2002). Human sex differences in social and non-social looking preferences, at 12 months of age. Infant Behavior and Development 25, (3), 319-325.

Lutchmaya, S., Baron-Cohen, S., Raggatt, P. (2002). Foetal testosterone and eye contact in 12month-old human infants. Infant Behavior and Development, 25, (3), 327-335.

Malatesta, C. Z., Grigoryev, P., Lamb, C., Albin, M., \& Culver, C. (1986). Emotion socialization and expressive development in preterm and full-term infants. Child Development, 57, (2), 316-330.

Manian, N. \& Bornstein M. H. (2009). Dynamics of emotion regulation in infants of clinically depressed and nondepressed mothers. Journal of Child Psychology and Psychiatry, and Allied Disciplines, 50, 1410-1418.

Moore, G.A., Quigley, K.M., Voegtline, K.M., Dipietro, J. (2015). Don't worry, be (moderately) happy: Mothers' anxiety and positivity during pregnancy independently predict lower mother-infant synchrony. Infant Behavior and Development, 42:60-68.

Mundy, P. (1995). Joint attention and social-emotional approach behavior in children with autism. Development and Psychopathology, 7(1), 63-82.

Mäntymaa M, Puura K, Luoma I, Salmelin R, Tamminen T (2004). Early mother-infant interaction, parental mental health and symptoms of behavioral and emotional problems in toddlers. Infant Behavior and Development, 27; 1: 134-49. 
Mäntymaa, M., Puura, K., Luoma, I., Latva, R., Salmelin, R. K., Tamminen, T. (2015). Shared pleasure in early mother-infant interaction: predicting lower levels of emotional and behavioral problems in the child and protecting against the influence of parental psychopathology. Infant Mental Health Journal, 36(2), 1-15.

Olino, T.M., Lopez-Duran, N.L., Kovacs, M., George,C.J., Gentzler, A.L., Shaw, D.S. (2011). Developmental trajectories of positive and negative affect in children at high and low familial risk for depressive disorder. Journal of Child Psychology and Psychiatry, 52(7), 792-799. doi:10.1111/j.1469-7610.2010.02331.x2010

Paavola L., Kemppinen K., Kumpulainen K., Moilanen I., Ebeling H. (2006). Maternal sensitivity, infant co-operation and early linguistic development: Some predictive relations. European Journal of Developmental Psychology, 3, 13-30.

Peltola, M. J., Yrttiaho, S., Puura, K., Proverbio, A. M., Mononen, N., Lehtimäki, T., \& Leppänen, J. M. (2014). Motherhood and oxytocin receptor genetic variation are associated with selective changes in electrocortical responses to infant facial expressions. Emotion, 14, 469-477.

Peltola, M. J., Forssman, L., Puura, K., van IJzendoorn, M. H., \& Leppänen, J. M. (2015). Attention to faces expressing negative emotion at 7 months predicts attachment security at 14 months. Child Development, 86, 1321-1332.

Pesonen, A.-K., Räikkönen, K., Heinonen, K., Komsi, N., Järvenpää, A.-L. and Strandberg, T. (2008). A Transactional Model of Temperamental Development: Evidence of a Relationship between Child Temperament and Maternal Stress over Five Years. Social Development, 17: 326-340. doi:10.1111/j.1467-9507.2007.00427.x

Puura, K., Davis, H., Cox, A., Tsiantis, J., Tamminen, T., Ispanovic-Radojkovic, V., Paradisiotou, A., Mäntymaa, M., Roberts, R., Dragonas, T., Layiou-Lignos, E., Dusoir, T., Rudic, N., Tenjovic, L., Vizacou, S. (2005). The European Early Promotion Project: Description of the Service and Evaluation Study. International Journal of Mental Health Promotion, 7(1), 17-31.

Puura, K., Guedeney, A., Mäntymaa, M., \& Tamminen, T. (2007). Detecting infants in need: How complicated measures are necessary. Infant Mental Health Journal, 28, 409-421.

Puura K, Mäntymaa M, Luoma I, Kaukonen P, Guedeney A, Salmelin R, Tamminen T. (2010). Infants' social withdrawal symptoms assessed with a direct infant observation method in primary health care. Infant Behavior and Development , 33(4), 579-88.

Ramsey, M.A., Gentzler, A.L. (2015). An upward spiral: Bidirectional associations between positive affect and positive aspects of close relationships across the life span. Developmental Review, 36, 58-104.

Rodrigues, S.M., Saslow, L.R., Garcia, N., John, O.P., Keltner, D. (2009). Oxytocin receptor genetic variation relates to empathy and stress reactivity in humans. Proc. Natl. Acad. Sci. U. S. A. 106, 21437-21441. 
Rolls, E. T. (1999). The brain and emotion. New York:Oxford University Press.

Rothbart, M. K. (1981). Measurement of temperament in infancy. Child Development, 52, 569-578.

Rothbart, M. K., Ahadi, S. A., \& Evans, D. E. (2000). Temperament and personality: Origins and outcomes. Journal of Personality and Social Psychology, 78(1), 122-135.

Rothbart, M. K. \& Bates, J. E. (2006). Temperament. In Damon, W. \& Lerner R. M.

(Editors-In-Chief) \& N. Eisenberg (Vol. Ed.), Handbook of Child Psychology, Volume3, Social, Emotional and Personality Development,.pp 99-168. John Wiley \& Sons, Inc., Hoboken, New Jersey.

Sallquist, J., Eisenberg, N., Spinrad, T.L., Gaertner, B.M., Eggum N.D., Zhou,N. (2010). Mothers’ and Children's Positive Emotion: Relations and Trajectories across Four Years. Social Development, 19, 4, 799-821.

Schelling, T. (1963). The Strategy of Conflict, New York, Oxford University Press.

Schore, A. N. (2001). The effects of a secure attachment relationship on right brain development, affect regulation, and infant mental health. Infant Mental Health Journal, 22:7-66.

Schore, A.N. (2017). All our sons: the developmental neurobiology and neuroendocrinology of boys at risk. Infant Mental Health Journal, 38, 15-52.

Schultz, W. (2000). Multiple reward signals in the brain.Nature Reviews: Neuroscience, 1, 199207.

Siegel, D.J. (2001). Toward an interpersonal neurobiology of the developing mind: Attachment relationships, “mindsight,” and neural integration. Infant Mental Health Journal, 22(1-2), 67-94.

Stern, D. N. (1971). A Micro-Analysis of Mother-Infant Interaction. Behavior Regulating Social Contact Between a Mother and her 3 1/2 Month-Old Twins. Journal of the American Academy of Child Psychiatry, 10, 3, 501-517.

Tamis-LeMonda, C. S., Briggs, R. D., McClowry, S. G., \& Snow, D. L. (2009). Maternal control and sensitivity, child gender, and maternal education in relation to children's behavioral outcomes in African American families. Journal of Applied Developmental Psychology, 30(3), 321-331.

Tamminen, T. (1990). Äidin masennus, imetys ja varhainen vuorovaikutus. Acta Universitatis Tamperensis, Ser. A, ISSN 0496-7909; vol. 304.

Tein, J.-Y.,Sandler, I.N.,,Zautra, A.J.(2000). Stressful life events, psychological distress, coping, and parenting of divorced mothers: A longitudinal study. Journal of Family Psychology, 14(1),27-41.

Tost, H., Kolachana, B., Hakimi, S., Lemaitre, H., Verchinski, B. A., Mattay, V. S., Weinberger, D. R., and Meyer-Lindenberg, A. (2010). A common allele in the oxytocin receptor gene (OXTR) impacts prosocial temperament and human hypothalamic-limbic structure and function. Proc. Natl. Acad. Sci. U.S.A. 107, 13936-13941. 
Trevarthen, C. and Aitken, K. J. (2001). Infant Intersubjectivity: Research, Theory, and Clinical Applications. Journal of Child Psychology and Psychiatry, 42: 3-48.

Tronick, E.Z. (1989). Emotions and emotional communication in infants. American Psychologist,, 44(2), 112-119.

Tronick, E.Z. (2007). The neurobehavioral and social-emotional development of infants and children. WW Norton \& Company

Wachs, T.D, Black, M.M., \& Engle, P.L. (2009). Maternal depression: A global threat to children's health, development, and behavior and to human rights. Child Development Perspectives, 3(1), 51-59. doi:10.1111/j.1750-8606.2008.00077.x

Watson, D. \& Tellegen. A. (1985). Toward a consensual structure of mood. Psychological Bulletin, 98, 219-235.

Wright, K. (1991). Vision and separation: Between mother and baby. Northvale, NJ: Jason Aronson.

Yrttiaho, S. Forssman, L., Kaatiala, J., \& Leppänen, JM. (2014). Developmental precursors of social brain networks: the emergence of attentional and cortical sensitivity to facial expressions in 5 to 7 months old infants. PLoS ONE 9(6): e100811. doi:10.1371/journal.pone.0100811.

Zhang, T. Y., \& Meaney, M. J. (2010). Epigenetics and the environmental regulation of the genome and its function. Annual Review of Psychology, 61, 439-466. 
Table 1. Characteristics of the continuous maternal and infant variables in the sample. Sample size varies between items due to missing data.

\begin{tabular}{lccccc}
\hline Variable & Median & Quartiles & Min, max & Mean & SD \\
\hline Shared pleasure (SP) sequences & & & & & \\
$\quad$ Frequency of SP ( $=113)$ & 1 & 0,4 & 0,26 & 2.7 & 3.6 \\
$\quad$ Mean duration (SP-MD) ${ }^{(1}(\mathrm{n}=80)$ & 1.0 & $0.5,1.5$ & $0.5,3.0$ & 1.1 & 0.6 \\
Mother & & & & & \\
$\quad$ Number of life events $(\mathrm{n}=109)$ & 1 & 0,2 & 0,6 & 1.4 & 1.3 \\
$\quad$ EPDS $^{(2}$ score $(\mathrm{n}=109)$ & 5 & 2,7 & 0,19 & 5.0 & 3.9
\end{tabular}

Infant

$\begin{array}{lccccc}\text { Age, days }(\mathrm{n}=113) & 213 & 211,216 & 207,243 & 214 & 4.5 \\ \operatorname{ADBB}^{(3} \text { score }(\mathrm{n}=113) & 4^{(6} & 1,5 & 0,11 & 3.3 & 2.3 \\ \operatorname{IBQ}^{(4}(\mathrm{n}=109) & & & & & \\ \text { Positive affectivity } & 4.4 & 3.9,4.8 & 2.9,6.1 & 4.4 & 0.6 \\ \text { Negative affectivity } & 2.9 & 2.6,3.3 & 1.7,4.4 & 2.9 & 0.5\end{array}$

$\operatorname{EAS}^{(5}(\mathrm{n}=113)$

$\begin{array}{lccccc}\text { Maternal sensitivity } & 5^{(7} & 4.0,6.0 & 3,7 & 5.0 & 1.1 \\ \text { Maternal structuring } & 5 & 4.0,6.0 & 2,7 & 4.7 & 1.2 \\ \text { Child responsiveness } & 5 & 4.0,5.5 & 3,7 & 4.9 & 1.1 \\ \text { Child involvement } & 5 & 4.0,5.0 & 3,7 & 4.6 & 1.2\end{array}$

1) for those having at least one SP sequence

2) Edinburgh Postnatal Depression Scale

3) Alarm Distress Baby Scale

4) Infant Behavior Questionnaire

5) Emotional Availability Scale

6) boys $4 ; 3,5 ; 0,7$, and girls $2.5 ; 0,5 ; 0,11, p=0.036$

${ }^{7)}$ boys $(\mathrm{n}=65) 5 ; 4,5 ; 3,7$, and girls $(\mathrm{n}=48) 5 ; 4.5,6 ; 3,7, p=0.03$ 
Table 2. Frequencies of the dichotomized maternal and infant variables in the sample.

Sample size varies between items due to missing data.

\begin{tabular}{ll}
\hline Variable & $\%$ \\
\hline
\end{tabular}

Shared pleasure (SP) sequences

One or more $(\mathrm{n}=113) \quad 71$

Mean duration (SP-MD) $)^{(1}$ longer than 0.5 seconds $(\mathrm{n}=80) \quad 75$

Mother

Life events

One or more $(n=109) \quad 73$

Still affecting mother $(n=79) \quad 48$

Infant

Boys $(n=65 / 113) \quad 58$

$\mathrm{ADBB}^{(2}$ score 4 or less $(\mathrm{n}=113)$

Genes $(n=96)$

$\begin{array}{ll}\text { rs6295 CC } & 27\end{array}$

rs4570625 GT or TT 38

$\operatorname{EAS}^{(3}(\mathrm{n}=113)$

Maternal sensitivity 5 or more $\quad 66^{(4}$

Maternal structuring 5 or more $\quad 60$

Child responsiveness 5 or more $\quad 65$

Child involvement 5 or more $\quad 59$

1) for those having at least one SP sequence

2) Alarm Distress Baby Scale

3) Emotional Availability Scale

4) boys $59 \%$, girls $75 \%, p=0.075$ 
Table 3. Continuous maternal and infant characteristics affecting statistically significantly or indicatively (in either sex or both sexes) a) the proportion of dyads having at least one shared pleasure sequence and b) the mean duration of SP sequences lasting longer than $0.5 \mathrm{~s}$ during a 5-minute free play situation, separately for mother-son and mother-daughter dyads.

\begin{tabular}{|c|c|c|c|c|c|c|}
\hline & & Medic & Quartiles & Medic & Quartiles & $p$ \\
\hline \multirow[t]{8}{*}{ Boys } & & \multicolumn{4}{|c|}{ Number of SP sequences } & \\
\hline & & \multicolumn{2}{|r|}{0} & \multicolumn{2}{|c|}{$>1$} & \\
\hline & EPDS score & 3.0 & $1.3,4.0$ & 5.0 & $2.0,9.0$ & 0.007 \\
\hline & IBQ positive affectivity & 4.0 & $3.6,4.5$ & 4.5 & $4.0,4.8$ & 0.061 \\
\hline & IBQ negative affectivity & 2.9 & $2.5,3.3$ & 2.9 & $2.6,3.3$ & ns \\
\hline & & \multicolumn{4}{|c|}{ Mean duration of SP sequences } & \\
\hline & & \multicolumn{2}{|c|}{$\leq 0.5 \mathrm{~s}$} & \multicolumn{2}{|c|}{$>0.5 \mathrm{~s}$} & \\
\hline & EPDS score & 8.5 & $6.8,10.0$ & 4.5 & $2.0,7.0$ & 0.002 \\
\hline \multirow[t]{8}{*}{ Girls } & & \multicolumn{4}{|c|}{ Number of SP sequences } & \\
\hline & & \multicolumn{2}{|r|}{0} & \multicolumn{2}{|c|}{$>1$} & \\
\hline & EPDS score & 3.0 & $1.0,6.0$ & 5.0 & $2.0,8.0$ & ns \\
\hline & IBQ positive affectivity & 4.6 & $4.1,4.9$ & 4.3 & $3.8,4.7$ & ns \\
\hline & IBQ negative affectivity & 2.6 & $2.3,2.9$ & 2.9 & $2.7,3.4$ & 0.007 \\
\hline & & \multicolumn{4}{|c|}{ Mean duration of SP sequences } & \\
\hline & & \multicolumn{2}{|c|}{$\leq 0.5 \mathrm{~s}$} & \multicolumn{2}{|c|}{$>0.5 \mathrm{~s}$} & \\
\hline & EPDS score & 8.0 & $1.8,10.5$ & 4.5 & $2.0,7.3$ & ns \\
\hline
\end{tabular}


Table 4. The results of backwards stepwise logistic regressions for having at least one shared pleasure (SP) sequence and having long (mean duration over 0.5 s) SP sequences in dyadic interaction in a free play situation involving mothers and their 7-month-old infants. The selection of explanatory variables was based on a pairwise significant or indicative $(p \leq 0.10)$ association with the respective outcome variable.

\begin{tabular}{|c|c|c|c|c|c|}
\hline Outcome variable & Categories (reference & OR & \multicolumn{2}{|c|}{$95 \%$ CI } & $p$ \\
\hline Explanatory variable & category in italics) & & & & \\
\hline Number of SP sequences $(n=94)^{(1}$ & 0 vs 1 or more & & & & \\
\hline \multicolumn{6}{|l|}{ Mother } \\
\hline EPDS score & continuous $^{(2}$ & 2.2 & 1.2 & 3.8 & 0.007 \\
\hline \multicolumn{6}{|l|}{ Infant } \\
\hline Responsiveness & 4 or less vs 5 or more & 8.9 & 2.8 & 28.6 & $<0.001$ \\
\hline Gene rs4570625 & GT or $T T$ vs GG & 5.7 & 1.8 & 17.8 & 0.003 \\
\hline
\end{tabular}

\footnotetext{
Mean duration of SP sequences $(n=78)^{(3} \quad 0.5 \mathrm{~s}$ or less vs over $0.5 \mathrm{~s}$
}

Mother

$\begin{array}{llllll}\text { EPDS score } & \text { continuous }^{*} & 0.4 & 0.2 & 0.9 & 0.030 \\ \text { Structuring } & \text { 4 or less vs 5 or more } & 3.7 & 1.1 & 12.9 & 0.040\end{array}$

Infant

$\begin{array}{llllll}\text { Involvement } \quad \text { 4 or less vs } 5 \text { or more } & 7.1 & 2.0 & 25.3 & 0.003\end{array}$

\footnotetext{
1) Variables entered (reference category in italics):

mother: life events still affecting (no vs yes), EPDS score (continuous), sensitivity and structuring (both 4 or less vs 5 or more)
}

infant: sex (boy vs girl), IBQ positive affectivity (continuous), IBQ negative affectivity (continuous), involvement and responsiveness (both 4 or less vs 5 or more), ADBB score (4 or less vs 5 or more), gene rs6295 (CC vs GG or CG), gene rs4570625 (GG vs GT or TT)

2) Square root-transformed

3) Variables entered (reference category in italics):

mother: EPDS score (continuous), sensitivity and structuring (both 4 or less vs 5 or more)

infant: sex (boy vs girl), involvement and responsiveness (both 4 or less vs 5 or more), ADBB score (4 or less vs 5 or more) 